\title{
Efficacy and safety of total glucosides of paeony combined with methotrexate and leflunomide for active rheumatoid arthritis: a meta-analysis
}

This article was published in the following Dove Press journal:

Drug Design, Development and Therapy

\section{Yao Huang \\ Hui Wang \\ Zhe Chen \\ Yu Wang \\ Kai Qin \\ Ying Huang \\ Xin $\mathrm{Ba}$ \\ Weiji Lin}

Shenghao Tu

Institute of Integrated Traditional Chinese and Western Medicine, Tongji Hospital, Tongji Medical College,

Huazhong University of Science and Technology, Wuhan, Hubei 430030,

People's Republic of China
Correspondence: Shenghao Tu Institute of Integrated Traditional Chinese and Western Medicine, Tongji Hospital,

Tongji Medical College, Huazhong University of Science and Technology,

No. 1095 Jie Fang Avenue, Hankou, Wuhan 430030, People's Republic of China

Tel +86I 397 I53 5353

Fax +862783663237

Email shtu@tjh.tjmu.edu.cn
Purpose: Total glucosides of paeony (TGP) have been confirmed to reduce hepatotoxicity caused by methotrexate (MTX) and leflunomide (LEF) in rheumatoid arthritis (RA). Nevertheless, high-quality evidence-based meta-analysis data on the issue are unavailable. This study aimed to evaluate the efficacy and safety of this combination treatment for RA. Materials and methods: PubMed, EMBASE, Web of Science, Cochrane Library, ClinicalTrials, Chinese Biomedical Literature database, China National Knowledge Internet, Wan Fang, and VIP were searched up to February 2019. Randomized controlled trials (RCTs) on the efficacy and safety of TGP combined MTX and LEF for RA were included.

Results: Eight RCTs were included in the final meta-analysis. Pooled results showed better therapeutic effects against RA in the TGP-treated group ( $R R=1.10,95 \% \mathrm{CI}: 1.04-1.16)$. The TGP+MTX+LEF group showed a reduced erythrocyte sedimentation rate $(\mathrm{MD}=-2.80 \mathrm{~mm} / \mathrm{h}$, 95\% CI: -5.08 - -0.52), C-reactive protein level (MD $=-4.17 \mathrm{mg} / \mathrm{L}, 95 \% \mathrm{CI}:-7.84--0.51)$, and rheumatoid factor $(\mathrm{MD}=-12.09 \mathrm{IU} / \mathrm{mL}, 95 \% \mathrm{CI}:-14.05--10.14)$. Besides, the combination treatment tended to benefit lipid profiles (total cholesterol: 95\% CI: $-1.27-0.06$; triglycerides: 95\% CI: -0.49 - -0.08 ; high-density lipoprotein cholesterol: $95 \%$ CI: $0.15-0.83$; and low-density lipoprotein cholesterol: $95 \% \mathrm{CI}:-0.54--0.02$ ). Adverse events, hepatotoxicity in particular, significantly decreased $(\mathrm{RR}=0.55,95 \% \mathrm{CI}: 0.38-0.80)$ in the TGP group.

Conclusion: Compared to MTX and LEF therapy, TGP combination treatment may be a more effective and safer strategy. It is advisable to apply TGP as an adjuvant given its hepatoprotective and possible lipid-regulating effect. However, further large-scale and highquality clinical trials are warranted, and the efficacy of TGP in terms of its effect on lipid profiles should be further confirmed.

Keywords: total glucosides of paeony, methotrexate, leflunomide, rheumatoid arthritis, meta-analysis

\section{Introduction}

Rheumatoid arthritis (RA) is a systematic autoimmune disease characterized by chronic inflammation of the synovium, synovial hyperplasia, pannus formation, and erosive lesions of the cartilage and bone tissue. It has a global prevalence of $0.24 \%$ and of $0.3 \%$ in China. ${ }^{1,2}$ The current therapeutic drugs for RA are mainly disease-modifying anti-rheumatic drugs (DMARDs), including conventional synthetic (cs) DMARDs, biological (b) DMARDs (tumour necrosis factor inhibitors), and targeted synthetic (ts) DMARDs (Janus kinase inhibitors). Among DMARDs, 
methotrexate (MTX) is recommended as the first strategy for the treatment of active RA by the European League Against Rheumatism (EULAR). ${ }^{3}$ When treatment with MTX plus short-term glucocorticoids (GC) fails, stratification such as switching to or adding another csDMARD is suggested. ${ }^{3}$ A previous meta-analysis indicated that leflunomide (LEF) in MTX non-responders can improve efficacy but increase the risk of liver toxicity. ${ }^{4}$ Despite the better efficacy and low cost of MTX and LEF combination treatment for active RA, hepatotoxicity caused by the therapy arouses much concern. Although bDMARDs and tsDMARDs show better responses and are safer than csDMARDs, high costs restrict their application., Therefore, there remains a demand for better pharmacologic strategies to treat RA.

Total glucosides of paeony (TGP) are biologically active compounds extracted from the roots of the traditional Chinese herb, Paeonia lactiflora Pallas. They predominantly comprise five monoterpene glycosides including paeoniflorin, oxypaeoniflorin, paeonin, albinorin, and benzoylpaeoniflorin. Paeoniflorin is the most abundant, accounting for $90 \%$ of the active components and the pharmacological effects of TGP. ${ }^{7,8}$ TGP has been approved as a disease-modifying drug for RA since 1998 by the China Food and Drug Administration and is now widely used to treat RA in China. Several experimental studies have indicated the anti-inflammatory, immunoregulatory, and analgesic effects of TGP. ${ }^{7-9}$ In addition, clinical studies have showed that compared to MTX and LEF therapy, TGP combined with MTX and LEF treatment significantly ameliorated manifestations of RA and reduced hepatotoxicity. ${ }^{10,11}$ Owing to the lack of a high-quality evidence-based study, we conducted this meta-analysis of randomized controlled trials (RCT) to comprehensively assess the efficacy and safety of TGP combined with MTX and LEF compared with those of MTX and LEF therapy, thus, assisting with the clinical decision for RA treatment.

\section{Materials and methods}

This review was conducted and reported in line with the Preferred Reporting Items for Systematic Reviews and Meta-Analyses (PRISMA) Statement protocol. ${ }^{12}$

\section{Search strategy}

To ascertain the efficacy and safety of TGP combined with MTX and LEF for active RA, we searched nine databases including PubMed, EMBASE, Web of Science, the Cochrane Library, ClinicalTrials, Chinese Biomedical Literature database (CBM), Wan Fang medical database, China National Knowledge Internet (CNKI), and VIP database.

The search strategies were as follows: 1. "total glucosides of paeony" OR TGP; 2. methotrexate OR MTX; 3. leflunomide OR LEF; 4. "rheumatoid arthritis" OR "rheumatism" OR "atrophic arthritis"; 5.1 AND 2 AND 3 AND 4; and 6. For Chinese databases, the terms "pa fu lin" OR "bai shao zong *" (for total glucosides of paeony), "jia an die ling" (for methotrexate), "lai fu mi te" (for leflunomide), and "guan jie yan" (for arthritis) were used.

\section{Inclusion and exclusion criteria}

The following were included: (1) studies that used TGP in combination with MTX and LEF to treat RA; (2) studies in which all enrolled patients were diagnosed with RA according to the recognized RA diagnostic criteria (the 1987 American College of Rheumatology [ACR] criteria or the 2010 ACR/ EULAR criteria); (3) studies in which there were no other treatment differences between the experimental and control group; (4) studies in which the duration of treatment was at least 12 weeks; (5) studies in which the data of interest were available; and (6) RCTs.

The following were excluded: (1) studies in which patients were not diagnosed with RA in accordance with the diagnostic criteria mentioned above; (2) studies in which there were additional treatment factors between the experimental and/or the control group; (3) incomplete or duplicative data or data of interest were not available; and (4) reviews, cross-design trials, comments, or case reports.

\section{Types of outcome measures}

The primary outcomes were therapeutic effects (TEs) and adverse events (AEs). The secondary outcomes were active arthritis evaluation indexes including erythrocyte sedimentation rate (ESR), C-reactive protein (CRP), rheumatoid factor (RF), disease activity score in 28 joints (DAS28), swollen joint count (SJC), tender joint count (TJC), and lipid profile indexes including total cholesterol (TC), triglyceride (TG), high-density lipoprotein cholesterol (HDL-C), and low-density lipoprotein (LDL-C). AEs included abnormal liver function (abnormalities were identified when either alanine aminotransferase or aspartate aminotransferase was at least 1.5 times above the upper limits of normal), leukopenia (leukocyte count $<4.0 \times 10^{9} / \mathrm{L}$ ), nausea and vomiting, gastrointestinal disorder, and diarrhoea (3-4 times a day). 


\section{Data extraction}

Two authors (Yao Huang and Hui Wang) independently browsed the title, abstract, and full text of the literature meeting the criteria. Any discrepancy was resolved by consensus with the corresponding author (Shenghao Tu). Details of the publication year, number of subjects, age, sex, disease duration, dosage, BMI, follow-up, and outcome indexes were extracted (Table 1). Only the endpoint data were applied in our meta-analysis because the initial level of all outcome indexes in eight RCTs were mostly identical between the TGP+MTX+LEF group and the MTX+LEF group.

\section{Assessment of methodological quality}

The quality of each study included was assessed according to the Cochrane Collaboration's risk of bias tool consisting of random sequence generation, allocation concealment, blinding of participants and personnel, blinding of outcome assessment, incomplete outcome data, selective reporting, and other biases. ${ }^{19}$

\section{Statistical analysis}

We used Rev Man 5.3 software and Stata 12.0 to evaluate the efficacy and safety of TGP in combination with MTX and LEF for treating active RA. A heterogeneity analysis was conducted using the $C h i^{2}$ and $I^{2}$ tests. The data were analysed using a fixed-effects model when statistical heterogeneity was low $\left(I^{2} \leq 50 \%\right.$ or $C h i^{2}$ test $\left.p<0.1\right)$; otherwise, the random-effect model was used. When heterogeneity was high, a meta-regression analysis was conducted using Stata 12.0 according to dosage and treatment duration, publication language, publication year, and combination with other drugs or not. Then, a subgroup analysis was performed to ascertain the possible reasons for heterogeneity. We used Rev Man 5.3 to perform a sensitivity analysis by eliminating studies in sequence and Stata 12.0 to obtain the figure for the sensitivity analysis and to evaluate the publication biases using Begg's and Egger's tests.

\section{Results}

\section{Study inclusions}

A total of 289 relevant studies were retrieved from nine databases by employing the above-mentioned search strategies. After removing duplicates, 209 studies were screened. Then, 179 records were excluded because of other diseases $(n=33)$, animal or cell experiments $(n=101)$, other medicines $(n=19)$, reviews or case reports $(n=26)$. Subsequently, 18 studies were eliminated owing to the use of combination medicines in these studies. The remaining 12 studies were further analysed, and two studies (Billix and Yu et al) were eliminated because they were not in accordance with the ACR/EULAR diagnostic criteria for RA. ${ }^{20,21}$ Furthermore, after careful comparison, some studies were thought to possibly be duplicate publications with different treatment durations. ${ }^{10,14,22,23}$ Finally, eight studies including 908 patients were analysed as shown in Figure $1 .{ }^{10,11,13-18}$

\section{Characteristics of the studies}

A total of eight trials including 463 RA cases and 465 controls that met our inclusion criteria were included. All the studies were conducted in China and published from 2011 to 2018. The TGP dosage ranged between 0.6 and $1.8 \mathrm{~g} /$ day. The dosages of MTX and LEF were equivalent between experiment and control groups with the MTX dosage ranging between 7.5 and $15 \mathrm{mg} /$ week and LEF dosage ranging between 10 and $20 \mathrm{mg} / \mathrm{d}$. The intervention duration in the included studies varied from 12 to 24 weeks. In the study by Xiang et al, all eligible patients were recruited from seven medical centres and the study by Chen et al was conducted in three centres, whereas the other six studies were performed in a single centre. As for the disease condition, DAS-ESR, the study by Tan et al required a score of more than 5.1, while in three studies patients with active RA having scores DAS28 $\geq 3.2$ were recruited..$^{10,11,14,18}$ In the study by Zheng et al, which was aimed at determining the effects of TGP on blood lipids, RA patients with dyslipidaemia were recruited. ${ }^{15}$ In the study by Tan et al, all patients used the same non-steroidal anti-inflammatory drug (NSAID, diclofanac sodium sustained release tablets $75 \mathrm{mg}$ qd) if necessary and folic acid tablets $10 \mathrm{mg} \mathrm{qw} .{ }^{18}$ In the study by Xiang et al, use of NSAID (diclofenac) and corticosteroids (10 mg/day, prednisone equivalent) was permitted. ${ }^{11}$ In the study by Zheng et al, the use of one NSAID was allowed. ${ }^{15}$ The study by Shi et al included four groups: MTX, MTX+TGP, MTX+LEF, and MTX+TGP $+\mathrm{LEF}$; only the needed data were included in the analysis. ${ }^{13}$ The characteristics of the included RCTs are listed in Table 1.

\section{Qualities of the studies included}

Most of the RCTs included exhibited poor methodological quality according to the Cochrane Collaboration's risk of bias tool criteria shown in Figure 2. Three trials described the random sequence generation and three provided dropout information specifically. However, sufficient information was unavailable for allocation concealment, blinding of 


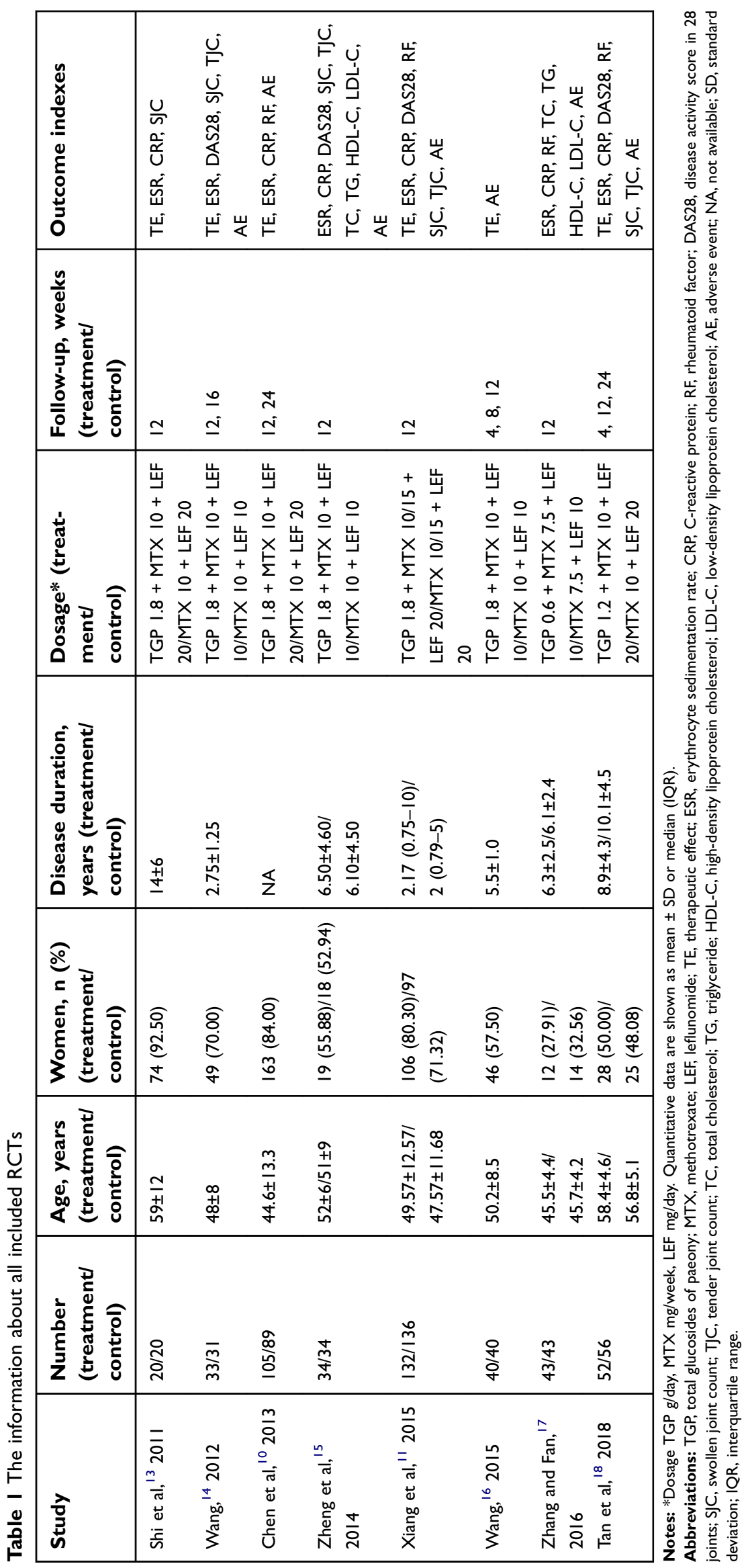




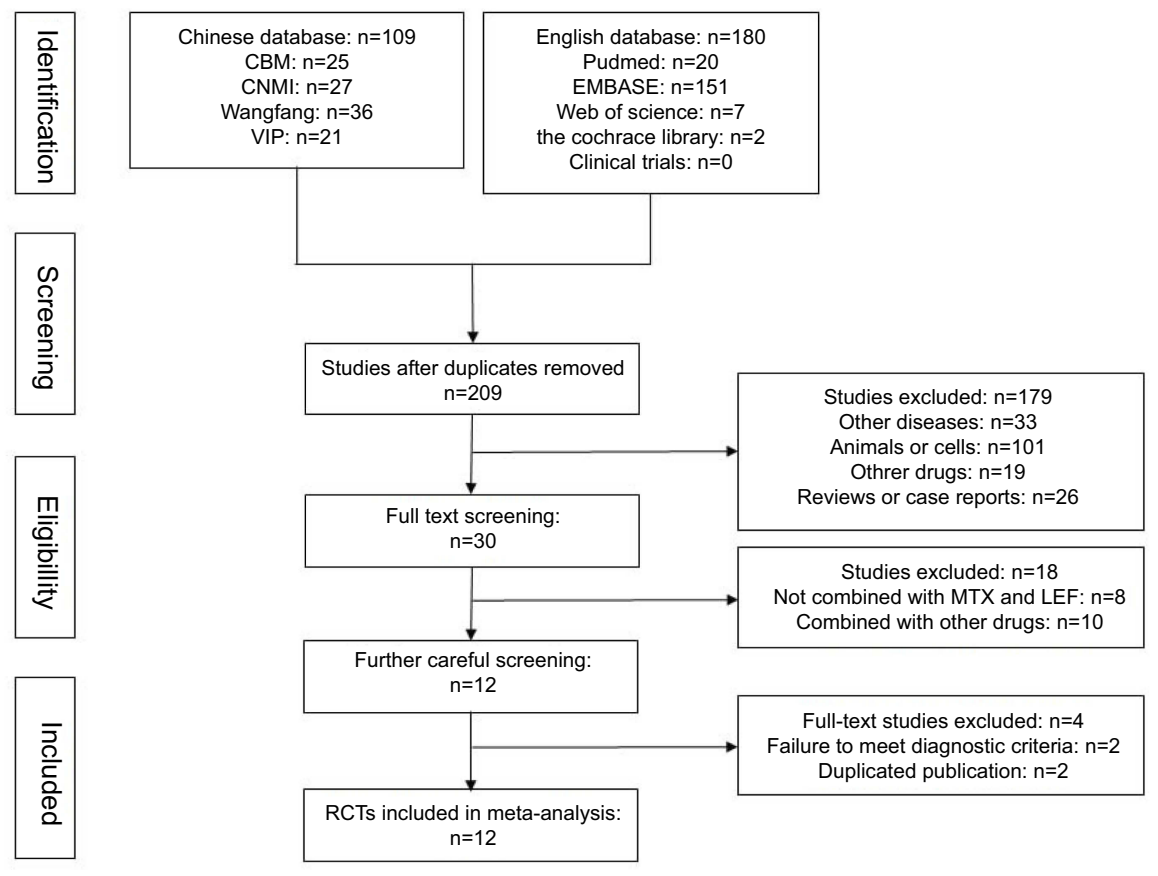

Figure I Flow diagram of study selection.

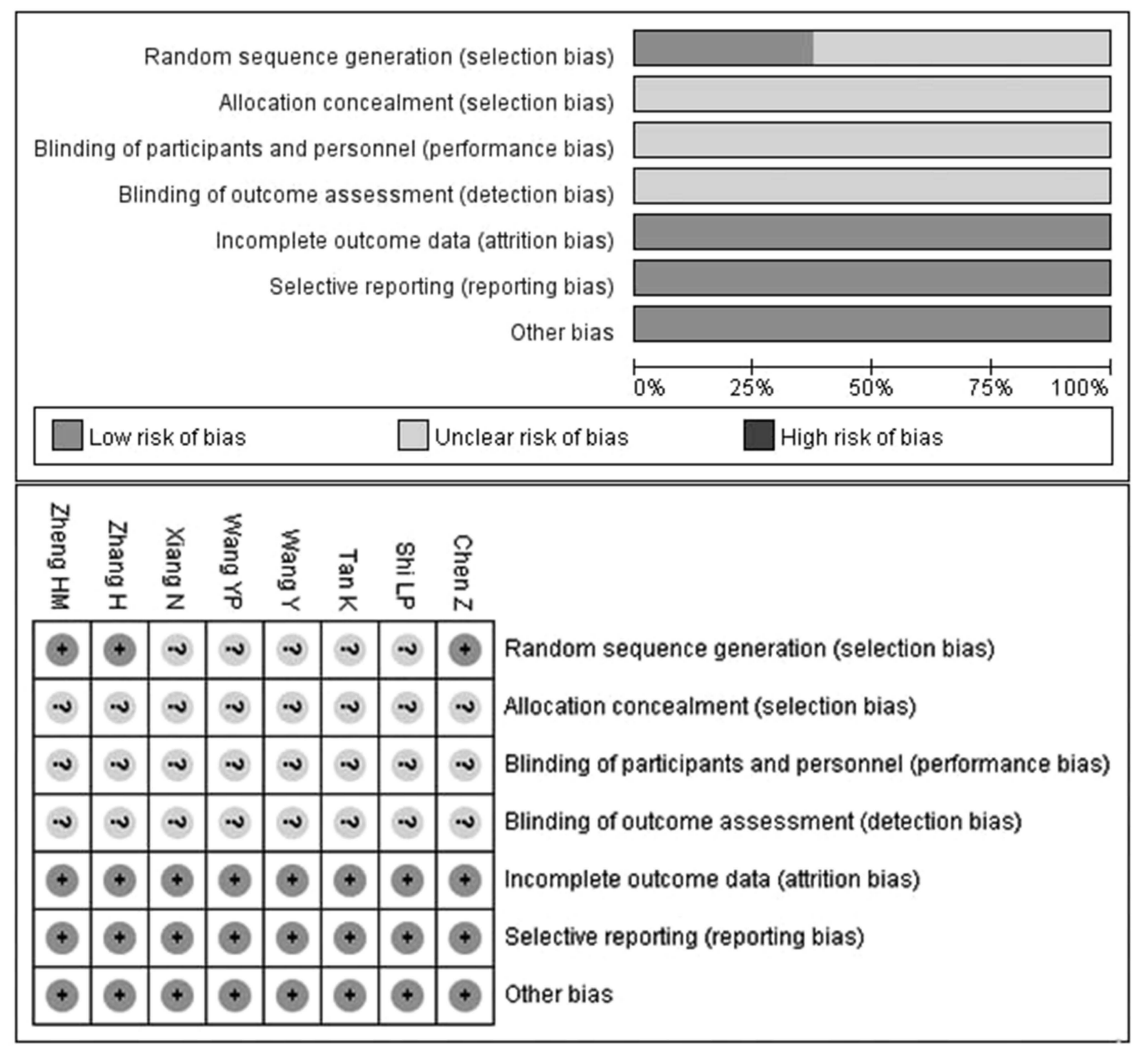

Figure 2 Risk of bias assessment.

Note: +, low risk of bias; ?, unclear risk of bias. 
participants and personnel, as well as blinding of outcome assessment.

\section{Meta-analysis}

\section{Arthritis-ameliorating effect}

The TEs were compared in six RCTs including 509 patients. As shown in Figure 3, the pooled results showed a slight improvement in the TEs of combination treatment plus TGP compared to those associated with MTX combined with LEF $(\mathrm{RR}=1.10,95 \% \mathrm{CI}: 1.04-1.16, p=0.002)$ based on the fixed-effect model $\left(I^{2}=22 \%, p=0.27\right)$. The pooled results for ESR showed TGP combined with MTX and LEF significantly ameliorated ESR $(\mathrm{MD}=-2.80 \mathrm{~mm} / \mathrm{h}, 95 \% \mathrm{CI}$ : $-5.08--0.52, p=0.02$ ) based on the random-effect model $\left(I^{2}=72 \%, p=0.002\right)$. Six studies showed that TGP+MTX $+\mathrm{LEF}$ therapy significantly reduced $\mathrm{CRP} \quad(\mathrm{MD}=$ $-4.17 \mathrm{mg} / \mathrm{L}, 95 \% \mathrm{CI}:-7.84--0.51, p=0.03)$ based on the random-effect model $\left(I^{2}=87 \%, p<0.00001\right)$. Four studies showed that TGP $+\mathrm{MTX}+\mathrm{LEF}$ treatment significantly decreased RF (MD $=-12.09 \mathrm{IU} / \mathrm{mL}, 95 \% \mathrm{CI}:-14.05$ $-10.14, p<0.00001)$ based on the fixed-effect model $\left(I^{2}=39 \%, p=0.18\right)$. Pooled results of DAS28, SJC, and TJC showed a slight improvement in the TGP+MTX+LEF group, but there were no statistically significant intergroup differences $(\mathrm{MD}=-0.79,95 \% \mathrm{CI}:-1.69--0.11, p=0.09$; $\mathrm{MD}=-0.77,95 \% \mathrm{CI}:-1.78-0.24, p=0.14 ; \mathrm{MD}=-0.55$, 95\% CI: $-1.61--0.50, p=0.30$; respectively) based on the random-effect model $\left(I^{2}=89 \%, p<0.00001 ; I^{2}=79 \%\right.$, $p=0.0009 ; I^{2}=72 \%, p=0.01$; respectively).

The results of the meta-regression analysis showed that the heterogeneity of ESR and CRP was not significantly related to treatment durations, dosage, publication year, publication language, or whether treatments were used in combination.

With regard to TE, ESR, and CRP, we also conducted a subgroup analysis to further assess whether the variation in the dosage of TGP (Figure 4) and follow-up (Figure 5) could contribute to the heterogeneity. In the dosage subgroup, the results obtained for TE and CRP suggested no significance ( $p=0.19$ and $p=1.00$, respectively), nor did those obtained for TE and ESR in the follow-up subgroup ( $p=0.38$ and $p=0.17$, respectively). However, in the dosage subgroup for ESR, $p=0.007$ indicated a significant difference, yet the improvement was not better with a higher dosage $(0.6 \mathrm{~g} / \mathrm{d}$ : $\mathrm{MD}=$ $-5.70 \mathrm{~mm} / \mathrm{h}, 95 \% \mathrm{CI}:-7.33--4.07, p<0.000001 ; 1.2 \mathrm{~g} / \mathrm{d}$ : $\mathrm{MD}=-5.50 \mathrm{~mm} / \mathrm{h}, 95 \% \mathrm{CI}:-10.86--0.14, p=0.04 ; 1.8 \mathrm{~g} / \mathrm{d}:$ $\mathrm{MD}=-1.51 \mathrm{~mm} / \mathrm{h}, 95 \% \mathrm{CI}:-3.56-0.55, p=0.15)$. Meanwhile, the change in CRP was statistically different in the follow-up subgroup ( $p=0.03$ ), and it seemed that a long follow-up led to greater improvement $(12 \mathrm{w}: \mathrm{MD}=-4.29 \mathrm{mg}$ / L, 95\% CI: $-8.03--0.56, p=0.02 ; 24 \mathrm{w}: \mathrm{MD}=-4.20 \mathrm{mg} / \mathrm{L}$, 95\% CI: $-7.50--0.90, p=0.01$; respectively) than did a short follow-up (4 w: $\mathrm{MD}=-0.03 \mathrm{mg} / \mathrm{L}, 95 \% \mathrm{CI}:-1.81-1.75$, $p=0.98$ ). However, other results did not indicate a dosagedependent or time-dependent relationship. We did not perform a meta-regression analysis or subgroup analysis with regard to RF, DAS28, SJC, and TJC owing to insufficient data.

\section{Lipid-regulating effect}

Only two RCTs studied the effect of TGP combined with MTX and LEF on lipid profiles as shown in Figure 6. ${ }^{15,17}$ Pooled results indicated that the TGP $+\mathrm{MTX}+\mathrm{LEF}$ combination treatment decreased the concentration of TC $(\mathrm{MD}=-0.61 \mathrm{mmol} / \mathrm{L}$; 95\% CI: $-1.27-0.06 ; p=0.07), \mathrm{TG}(\mathrm{MD}=-0.28 \mathrm{mmol} / \mathrm{L} ; 95 \%$ CI: $-0.49--0.08 ; p=0.007)$, and LDL-C (MD $=-0.28 \mathrm{mmol} /$ $\mathrm{L} ; 95 \% \mathrm{CI}:-0.54--0.02 ; p=0.03)$, while increasing the HDL$\mathrm{C}$ concentration $(\mathrm{MD}=0.49 \mathrm{mmol} / \mathrm{L} ; 95 \% \mathrm{CI}: 0.15-0.83$; $p=0.005)$.

\section{Adverse events}

As shown in Figure 7, seven studies showed AEs (summarized in Table 2) and the pooled results revealed a significantly lower rate of AEs caused by combination treatment plus TGP $(\mathrm{RR}=0.55,95 \% \mathrm{CI}: 0.38-0.80$, $p=0.002)$ based on the random-effect model $\left(I^{2}=72 \%\right.$, $p=0.001$ ). When the study by Xiang et al was eliminated, the heterogeneity significantly reduced ( $I^{2}$ reducing from $72 \%$ to $0 \%) .{ }^{11}$ AEs were not mentioned in the study by Shi et al. ${ }^{13}$ Five RCTs reported abnormal liver function, and one patient in the MTX+LEF group dropped out because of significantly elevated liver enzymes. ${ }^{10,11,14,16,18}$ Five RCTs reported leukopenia, and three patients dropped out because of a severe reduction in the leukocyte count, which also occurred in the MTX and LEF treatment group. ${ }^{10,11,14,16,18}$ Four RCTs reported diarrhoea, and one patient dropped out because of a severe condition. ${ }^{10,11,14,17}$ The pooled results indicated that the TGP $+\mathrm{MTX}+\mathrm{LEF}$ combination treatment significantly lowered occurrence of abnormal liver function $(\mathrm{RR}=0.69,95 \% \mathrm{CI}$ : $0.37-1.28, p<0.0001$ ), but there were no significant difference in the occurrence of leukopenia $(\mathrm{RR}=0.35$, 95\% CI: $0.24-0.52, p=0.24)$, nausea and vomiting (RR $=0.55,95 \% \mathrm{CI}: 0.28-1.07, p=0.08)$, gastrointestinal disorders $(\mathrm{RR}=0.66,95 \% \mathrm{CI}: 0.40-1.09, p=0.11)$ and diarrhoea $(\mathrm{RR}=4.02,95 \% \mathrm{CI}: 0.68-23.80, p=0.12)$. Besides dropouts, the AEs mentioned above resolved or disappeared 


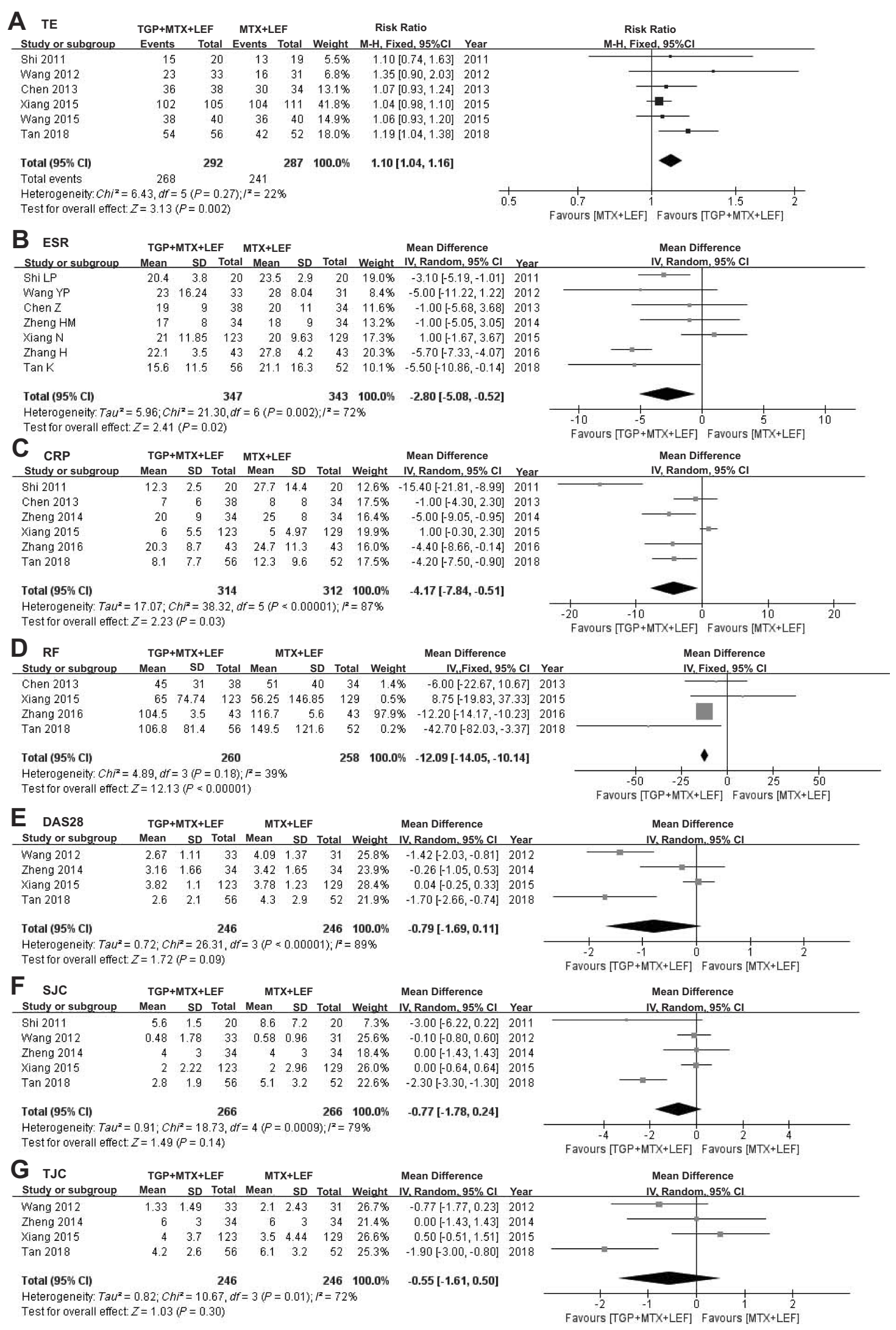

Figure 3 The pooled effects of TGP combined with MTX and LEF on TE, ESR, CRP, RF, DAS28, SJC, and TJC in cases of RA. Forest plots comparing TGP plus MTX and LEF with MTX and LEF. (A) TE; (B) ESR; (C) CRP; (D) RF; (E) DAS28; (F) SJC; (G) TJC.

Abbreviations: TGP, total glucosides of paeony; MTX, methotrexate; LEF, leflunomide; TE, therapeutic effect; ESR, erythrocyte sedimentation rate; CRP, C-reactive protein; RF, rheumatoid factor; DAS28, disease activity score in 28 joints; SJC, swollen joint count; TJC, tender joint count. 

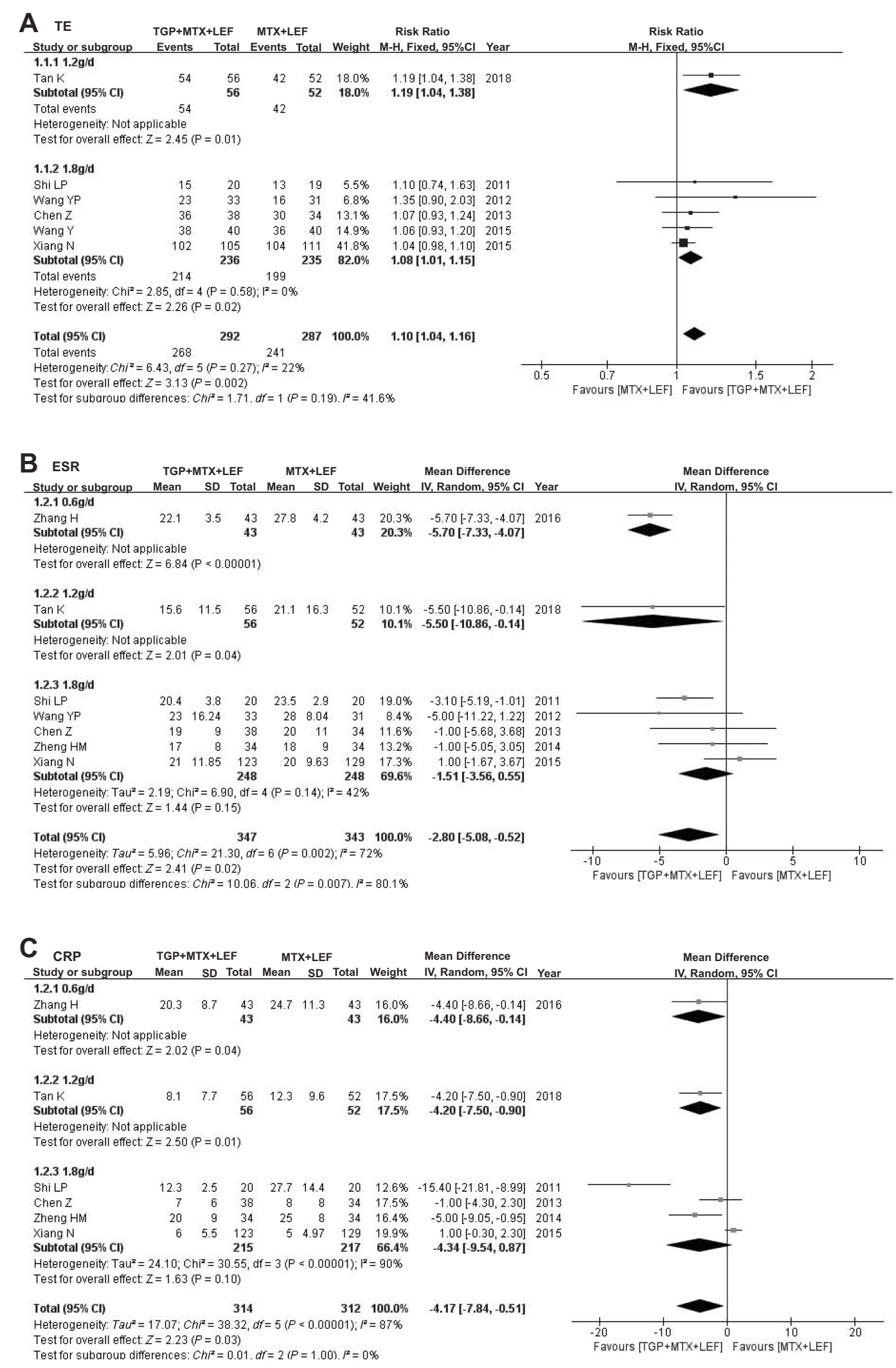

Figure 4 Subgroup analysis of TE, ESR, and CRP based on the dosage of TGP. Forest plots comparing TGP plus MTX and LEF with MTX and LEF. (A) TE; (B) ESR; (C) CRP. Abbreviations: TGP, total glucosides of paeony; MTX, methotrexate; LEF, leflunomide; TE, therapeutic effect; ESR, erythrocyte sedimentation rate; CRP, C-reactive protein. 


\section{A TE}

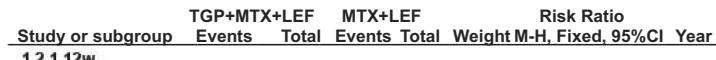
1.2.112w

\begin{tabular}{|c|c|c|c|c|c|c|}
\hline $\mathbf{w}$ & & & & & & \\
\hline Shi LP & 15 & 20 & 13 & 19 & $4.5 \%$ & $1.10[0.74,1.63]$ \\
\hline Wang YP & 23 & 33 & 16 & 31 & $5.6 \%$ & $1.35[0.90,2.03]$ \\
\hline Chen $Z$ & 68 & 83 & 47 & 63 & $18.1 \%$ & $1.10[0.92,1.31]$ \\
\hline Wang $Y$ & 38 & 40 & 36 & 40 & $12.2 \%$ & $1.06[0.93,1.20]$ \\
\hline Xiang $\mathrm{N}$ & 102 & 105 & 104 & 111 & $34.2 \%$ & $1.04[0.98,1.10]$ \\
\hline Subtotal $(95 \% \mathrm{Cl})$ & & 281 & & 264 & $74.6 \%$ & $1.08[1.01,1.16]$ \\
\hline Total events & 246 & & 216 & & & \\
\hline rogeneit & 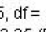 & & $i^{2}=0$ & & & \\
\hline
\end{tabular}

Test for overall effect: $Z=2.25(P=0.02)$

\subsubsection{4w}

Chen Z

Tan K

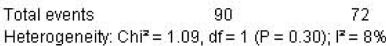

Test for overall effect: $Z=2.56(P=0.01)$

$\begin{array}{lllll}\text { Total }(95 \% \mathrm{Cl}) & 375 & 350 & 100.0 \% & 1.10[1.04,1.16]\end{array}$

Total events $\quad 336 \quad 288$

Heterogeneity: $C h r^{2}=6.45, d f=6(P=0.37) ; P$

Test for subaroun differences: $C i^{2}=0.77 . d f=1(P=0.38), I^{2}=0 \%$

$\begin{array}{llll}34 & 10.7 \% & 1.07[0.93,1.24] & 2013 \\ 52 & 14.7 \% & 1.19[1.04,1.38] & 2018\end{array}$

$8625.4 \%$

$1.14[1.03,1.27]$

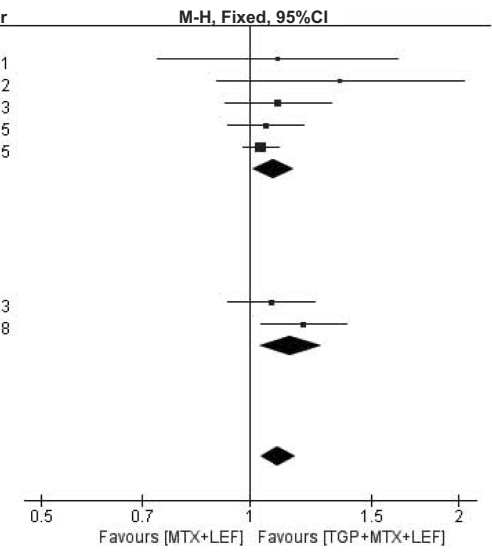

M-H, Fixed, $95 \% \mathrm{Cl}$

B ESR

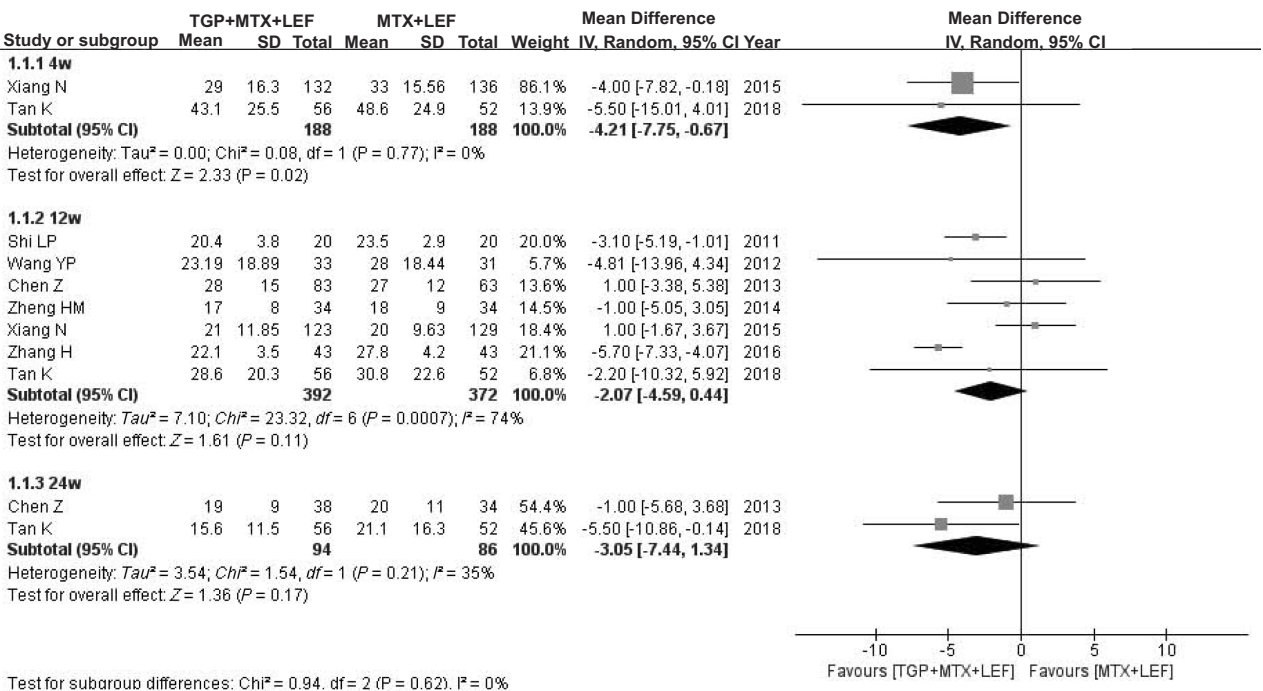

Test for subaroun differences: $\mathrm{Chi}^{2}=0.94 . \mathrm{df}=2(\mathrm{P}=0.62) . \mathrm{I}^{\mathrm{p}}=0 \%$

C $\mathrm{CRP}$

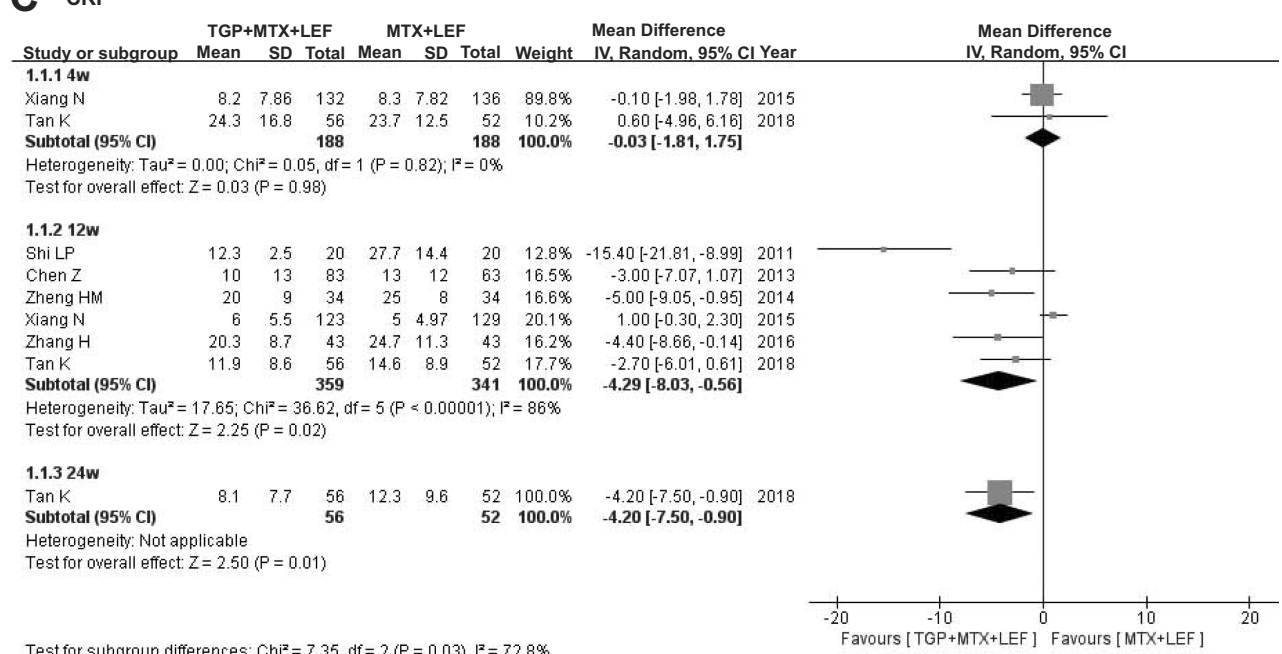

Test for subaroun differences: $\mathrm{Chi}^{2}=7.35 . \mathrm{df}=2(\mathrm{P}=0.03) \cdot \mathrm{I}^{\mathrm{2}}=72.8 \%$

Figure 5 Subgroup analysis of TE, ESR, and CRP based on follow-up. Forest plots comparing TGP plus MTX and LEF with MTX and LEF. (A) TE; (B) ESR; (C) CRP. Abbreviations: TGP, total glucosides of paeony; MTX, methotrexate; LEF, leflunomide; TE, therapeutic effect; ESR, erythrocyte sedimentation rate; CRP, C-reactive protein; w, weeks. 


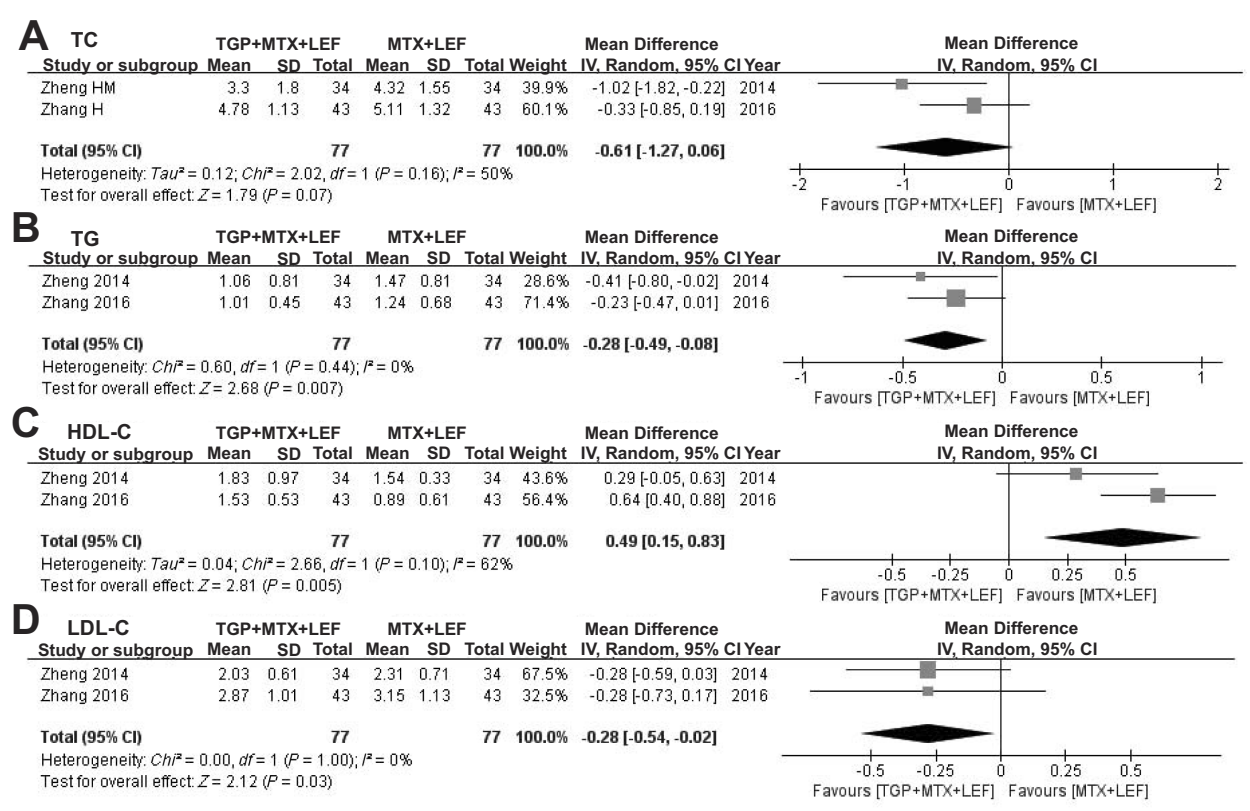

Figure 6 Pooled effects of TGP combined with MTX and LEF on TC, TG, HDL-C, and LDL-C in cases of RA. Forest plots comparing TGP plus MTX and LEF with MTX and LEF. (A) TC; (B) TG; (C) HDL-C; (D) LDL-C.

Abbreviations: TE, therapeutic effect; TGP, total glucosides of paeony; MTX, methotrexate; LEF, leflunomide; TC, total cholesterol; TG, triglyceride; HDL-C, high-density lipoprotein cholesterol; LDL-C, low-density lipoprotein cholesterol.

after discontinuing the medication transiently, reduction of dosage and symptomatic treatment.

\section{Sensitivity analysis}

In the sensitivity analysis (Figure 8), the heterogeneity of ESR significantly reduced when the study by Xiang et al or Zhang and Fan was removed ( $I^{2}$ reduced from $79 \%$ to $42 \%$ and $43 \%$, respectively). ${ }^{11,17}$ Moreover, when the study by Shi et al or Zhang and Fan was omitted, there was no statistical difference in ESR. ${ }^{13,17}$ No significant change in heterogeneity related to CRP was observed. Nevertheless, there was no statistical difference between the TGP+MTX+LEF and MTX+LEF groups with the removal of the study by Shi et al, Zheng et al or Tan et al. $^{13,15,18}$ There was no significant change in heterogeneity concerning DAS28, however, interestingly, a statistical difference arose when the study by Xiang et al was eliminated. ${ }^{11}$ The heterogeneity of SJC and TJC significantly reduced when the study by Tan et al was removed $\left(I^{2}\right.$ reduced from $79 \%$ to $7 \%$ and from $72 \%$ to $36 \%$, respectively). ${ }^{18}$

\section{Publication bias}

Publication bias was estimated using Begg's (Figure 9) and Egger's test. Studies with $p$-values greater than 0.05 were deemed to have low heterogeneity. The results signified that there was negligible bias associated with TE $(p=0.116), \operatorname{ESR}(p=0.598), \operatorname{RF}(p=0.853)$, DAS28 $(p=0.205)$, SJC $(p=0.370)$, and TJC $(p=0.977)$ except for $\mathrm{CRP}(p=0.006)$ and $\mathrm{AE}(p=0.007)$. Taking the possible publication bias into account, the significant CRPlowering and AE-lowering effects need further verification.

\section{Discussion}

The data from our current study indicated that the TGP $+\mathrm{MTX}+\mathrm{LEF}$ combination treatment could enhance treatment effects and reduce the levels of ESR, CRP, and RF, while having little impact on DAS28, STC, and TJC. There was little evidence showing that therapy plus TGP could lower the concentrations of TC, TG, and LDL-C and increase the concentration of HDL-C simultaneously. In addition, the TGP+MTX+LEF combination treatment significantly lowered the occurrence of abnormal liver function.

The results of the subgroup analysis suggested that the efficacy of TGP was not dependent on dosage and intervention time. One possible reason was that data from RCTs with different dosages and intervention times were not sufficient to support the conclusion. Another reason was that all RCTs included were of a low quality which might lead to false-positive or false-negative results owing to subjectivity. Moreover, the different dosages of MTX 


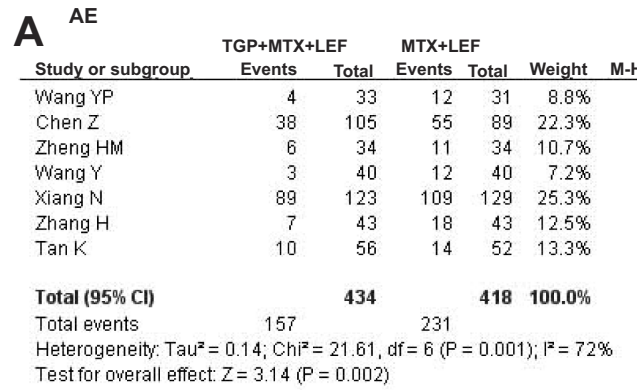

B Abnormal liver function
Risk Ratio Risk Ratio $0.31[0.11,0.87] 2012$ $0.59[0.43,0.79] 2013$ $0.55[0.23,1.31] 2014$ $0.25[0.08,0.82] 2015$ $0.86[0.75,0.98] 2015$ $\begin{array}{ll}0.86[0.75,0.98] & 2015 \\ 0.39[0.18,0.83] & 2016\end{array}$ $0.66[0.32,1.36] 2018$

$0.55[0.38,0.80]$

\begin{tabular}{|c|c|c|c|c|c|c|c|}
\hline Study or subgroup. & Events & Total Ev & $\begin{array}{l}\text { TX+L } \\
\text { is To } \\
\end{array}$ & & ight $M-$ & $\begin{array}{l}\text { Risk Ratio } \\
\text { Fixed, } 95 \% \mathrm{Cl} \text { Year }\end{array}$ & \\
\hline Wang YP & 2 & 33 & 9 & 31 & $11.4 \%$ & $0.21[0.05,0.89]$ & 201 \\
\hline Chen $Z$ & 10 & 105 & 31 & 89 & $41.3 \%$ & $0.27[0.14,0.53]$ & 201 \\
\hline Wang $Y$ & 1 & 40 & 4 & 40 & $4.9 \%$ & $0.25[0.03,2.14]$ & 201 \\
\hline Xiang $N$ & 14 & 123 & 30 & 129 & $36.0 \%$ & $0.49[0.27,0.88]$ & 201 \\
\hline Tan $\mathrm{K}$ & 2 & 56 & 5 & 52 & $6.4 \%$ & $0.37[0.08,1.83]$ & 201 \\
\hline Total $(95 \% \mathrm{Cl})$ & & 357 & & 341 & $100.0 \%$ & $0.35[0.24,0.52]$ & \\
\hline Total events & 29 & & 79 & & & & \\
\hline \multicolumn{8}{|c|}{ Heterogeneity: $\mathrm{Ch}^{2}=2.40, \mathrm{df}=4(\mathrm{P}=0.66) ;\left.\right|^{2}=0 \%$} \\
\hline
\end{tabular}

Test for overall effect $Z=5.25$ ( $P \leq 0.00001)$

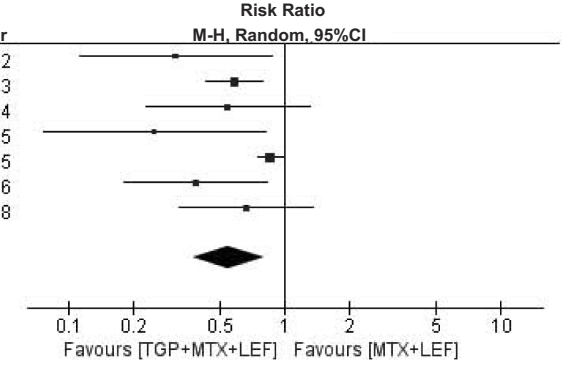
C Abnormal liver function TGP+MTX+LEF MTX+LEF Risk Ratio

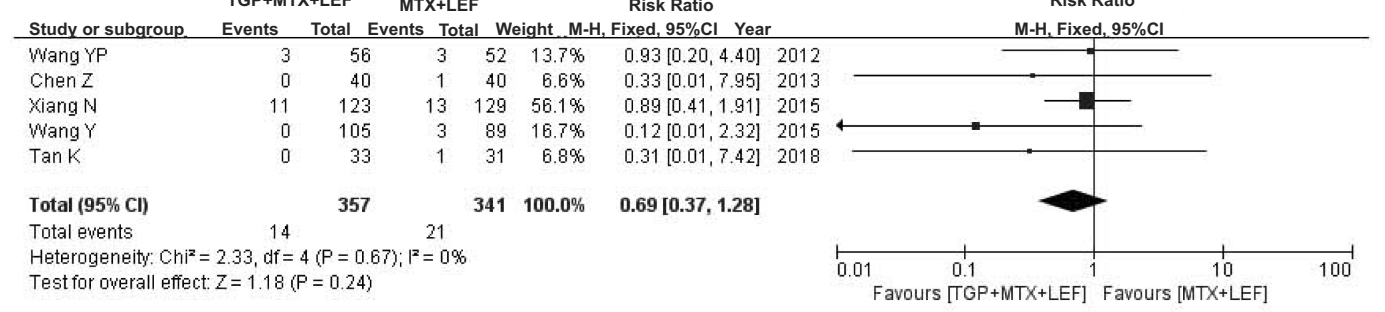

D Nausea and vomiting

$$
\text { TGP+MTX+LEF MTX+LEF Risk Ratio }
$$

Study or subgroup Events Total Events Total Weight M-H, Fixed, $95 \% \mathrm{Cl}$ Year $\begin{array}{lllllll}\text { Wang YP } & 0 & 33 & 0 & 31 & \text { Not estimable } 2012\end{array}$ Chen $Z$

Chenz

Tang $\mathrm{N}$

$\begin{array}{rrrrr}0 & 33 & 0 & 31 & \\ 2 & 105 & 3 & 89 & 14.8 \% \\ 9 & 123 & 16 & 129 & 71.1 \%\end{array}$

Not estimable 2012 $0.57[0.10,3.31]$
$0.59[0.27,1.28]$
2015

Tan K

$1 \quad 56$

$3 \quad 52 \quad 14.2 \%$

$0.31[0.03,2.88] 2018$

$\begin{array}{lllll}\text { Total }(95 \% \mathrm{Cl}) & 317 & 301 & 100.0 \% & 0.55[0.28,1.07]\end{array}$

Total events $12 \quad 22$

Heterogeneity: $\mathrm{Chi}^{2}=0.29, \mathrm{df}=2(\mathrm{P}=0.87) ; \mathrm{I}^{2}=0 \%$

Test for overall effect: $Z=1.75(P=0.08)$

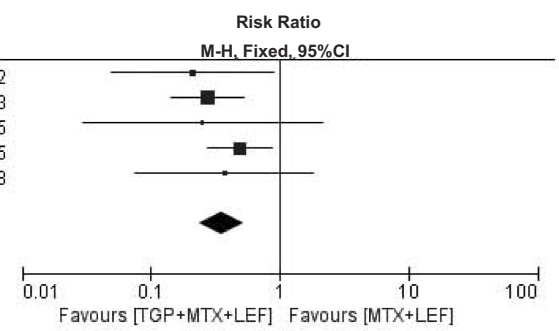

E Gastrointestinal disorder

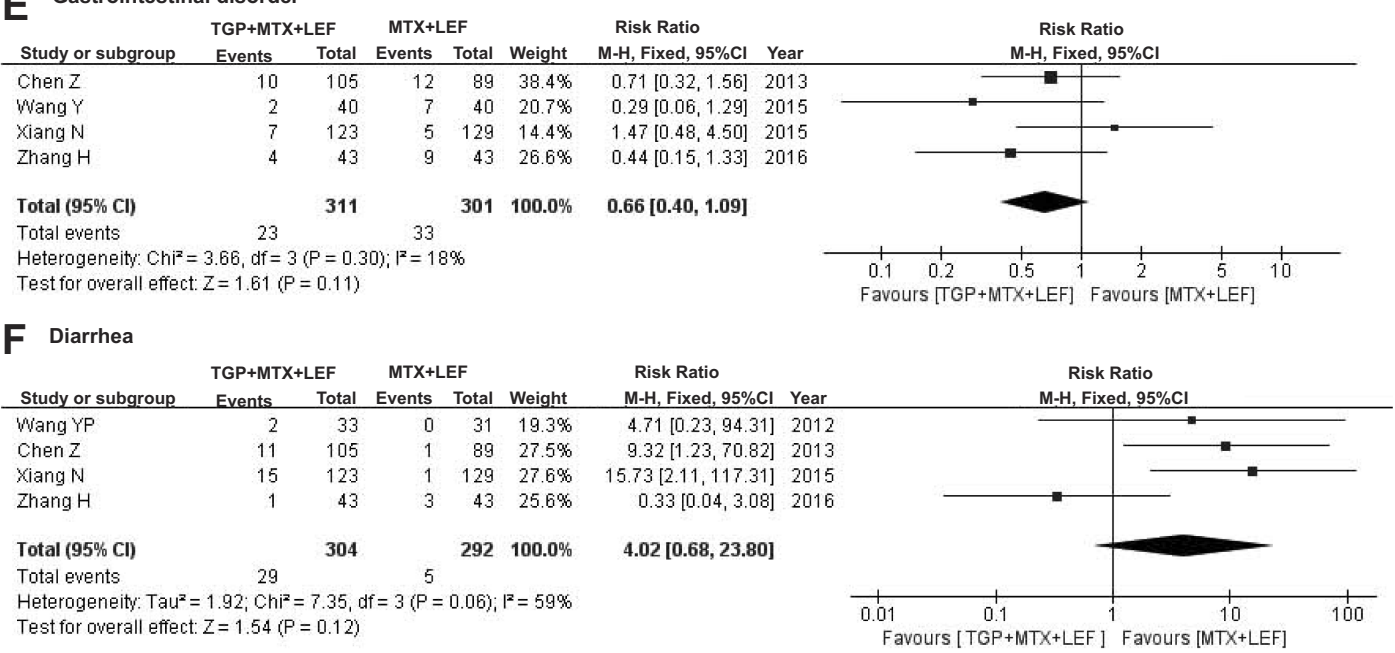

Figure 7 Pooled effects of AEs of TGP combined with MTX and LEF for RA. Forest plots comparing TGP plus MTX and LEF with MTX and LEF treatment. (A) AE; (B) Abnormal liver function; (C) Leukopenia; (D) Nausea and vomiting; (E) Gastrointestinal disorder; (F) Diarrhoea.

Abbreviations: AE, adverse event; TGP, total glucosides of paeony; MTX, methotrexate; LEF, leflunomide. 
Table 2 The AEs about all included RCTs

\begin{tabular}{|c|c|c|c|c|}
\hline \multirow[t]{2}{*}{ Adverse events } & \multicolumn{2}{|c|}{$\begin{array}{l}\text { TGP + } \\
\text { MTX + LEF }\end{array}$} & \multicolumn{2}{|c|}{$\begin{array}{l}\text { MTX + } \\
\text { LEF }\end{array}$} \\
\hline & $\mathbf{N}$ & Total & $\mathbf{N}$ & Total \\
\hline Abnormal liver function ${ }^{10,11,16,18,14}$ & 29 & 357 & 79 & 341 \\
\hline Leukopenia ${ }^{11,10,14,16,18}$ & 14 & 357 & 21 & 341 \\
\hline Nausea and vomiting ${ }^{10,11,14,18}$ & 12 & 317 & 22 & 301 \\
\hline Gastrointestinal disorder ${ }^{10,11,16,17}$ & 23 & 311 & 33 & 301 \\
\hline Diarrhea $^{10,11,14,17}$ & 29 & 304 & 5 & 292 \\
\hline Abdominal pain ${ }^{10,11}$ & 9 & 228 & 12 & 218 \\
\hline Anorexia ${ }^{11,17}$ & 19 & 166 & 23 & 172 \\
\hline Alopecia $^{10,11}$ & 4 & 156 & 9 & 160 \\
\hline Hypertension"I & 4 & 123 & 5 & 129 \\
\hline Oral mucosa erosion" & 0 & 123 & 2 & 129 \\
\hline Dizziness" & 2 & 123 & 3 & 129 \\
\hline Headache ${ }^{\prime \prime}$ & I & 123 & 0 & 129 \\
\hline Rash/Pruritus ${ }^{14,17,18}$ & 3 & 132 & 4 & 126 \\
\hline Abnormal renal function ${ }^{18}$ & I & 56 & I & 52 \\
\hline
\end{tabular}

Abbreviations: $A E$, adverse event; RCTs, randomized controlled trials; TGP, total glucosides of peony; MTX, methotrexate; LEF, leflunomide.

and LEF could contribute to the diversity and complexity of the combination therapy. Additional trials of various dosage combinations and of high quality should be conducted to determine the optimal therapeutic regimen. Considering the changes in the sensitivity analysis and publication bias, careful attention should be paid to outcomes associated with ESR, CRP and DAS28.

Some studies can help explain the efficacy of TGP in the treatment of RA. To begin with, TGP exerts a marked anti-inflammatory effect. The potential mechanism may be attributed to factors such as the modulation of proinflammatory mediators, mediation of cyclic adenosine monophosphate (cAMP) levels, suppression of the NF$\kappa \mathrm{B}$ signalling pathway and phosphorylated mitogenactivated protein kinase (MAPK) signalling molecules. ${ }^{24}$ Second, the immunoregulatory properties of TGP make it suitable for wide application in autoimmune diseases owing to the modulation of various immune-mediated inflammatory pathways such as regulation of the miR124/STAT3 pathway and blocking of TLR2/4/5. ${ }^{25,26}$ Furthermore, in several studies a consensus has been reached on analgesic effects of TGP, which are partly regulated by inhibition of the extracellular signalregulated protein kinase pathway and mediated by $\kappa$ opioid receptors and $\alpha 2$-adrenoceptors in the central nervous system. ${ }^{27}$ Besides, inhibition of synovial hypertrophy and neovascularization also plays a vital role in the treatment of arthritis. ${ }^{7}$ In view of the above modern pharmacological evidence, TGP can be administrated in various autoimmune disorders. In addition to RA, TGP have been commonly prescribed for diseases of ankylosing spondylitis, primary Sjogren's syndrome, oral lichen planus, and alopecia areata. ${ }^{28-32}$

Increasing evidence demonstrates that patients with RA are at excessive risk of cardiovascular disease (CVD) and dyslipidaemia is one of the risk factors. ${ }^{33}$ A meta-analysis of 24 studies in which mortality was reported in patients with RA indicated a $50 \%$ increased risk of CVD-related death. ${ }^{34}$ Recommendations for RA management according to EULAR 2016 include screening, identification of CVD risk factors, and CVD risk management. ${ }^{3}$ The excessive risk displayed in patients with RA may be influenced by pharmacological treatment to a certain degree such as treatment with GC, NSAIDs, MTX, and LEF. ${ }^{34}$ Therefore, not only did we assess the arthritis-ameliorating effect of TGP, but also evaluated its effect on lipid profiles. However, additional supporting data are required due to insufficient research on the topic. The lipid-regulating effect of TGP has also been confirmed in an animal models of atherosclerosis. ${ }^{35}$ We recommend that additional clinical and basic research should be performed on TGP regulation of blood lipids for the treatment of RA in the future.

Notable among the findings was that fewer AEs were associated with the TGP combination treatment than those associated with MTX and LEF therapy, especially when there was an emphasis on hepatotoxicity, which is indeed encouraging news for patients who are unable to tolerate MTX+LEF treatment. The precise hepatic mechanism of the effect of TGP in humans has not been clarified. However, studies conducted using animal models have indicated that paeoniflorin, the principal component of TGP, can ameliorate liver fibrosis and delay the progression of non-alcoholic fatty liver disease by regulating IL13 production and various intracellular pathway activities. $^{36,37}$ There was an increasing tendency for the occurrence of diarrhoea in the TGP group but no statistical intergroup difference was found. Considering any possible publication bias, whether TGP combination treatment can reduce AEs needs further validation.

There are some advantages of our study. To start with, we established strict inclusion criteria to exclude articles that did not meet the ACR/EULAR diagnostic criteria. Second, with verification of research design, sample size, and implementation location, we avoided 

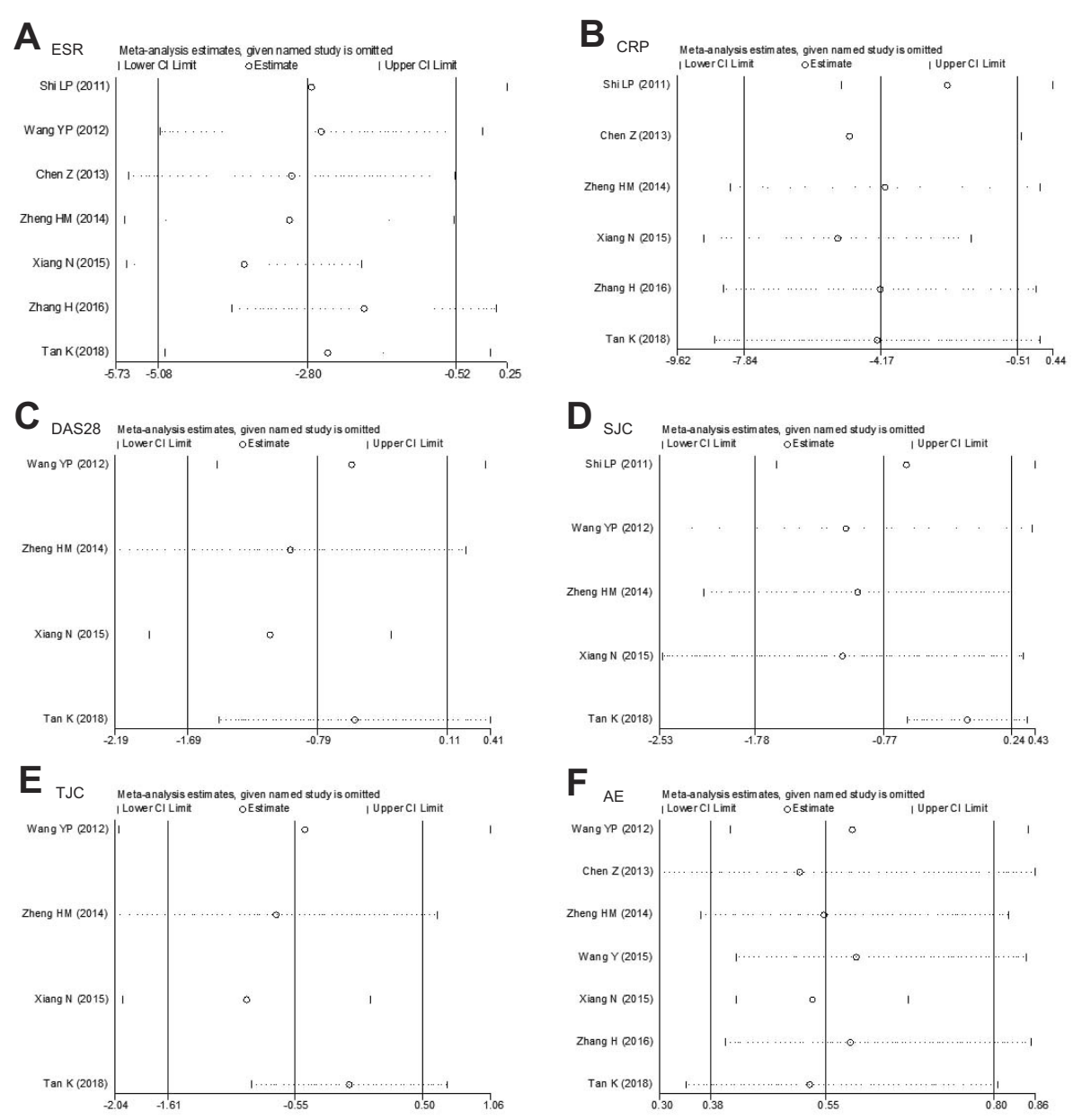

Figure 8 Sensitivity analysis. (A) ESR; (B) CRP; (C) DAS28; (D) SJC; (E) TJC; (F) AE.

Abbreviations: ESR, erythrocyte sedimentation rate; CRP, C-reactive protein; DAS28, disease activity score in 28 joints; SJC, swollen joint count; TJC, tender joint count; $A E$, adverse event.

possible duplicate publications. Moreover, we performed a meta-regression analysis and a subgroup analysis to determine sources of heterogeneity. To assess the credibility and robustness of the results, we used Begg's and Egger's tests as well as a sensitivity analysis. Last but not least, AEs of TGP were fully detailed in our metaanalysis which is not common in research of traditional Chinese medicine. Nonetheless, our meta-analysis has several limitations that should be considered. First, all of the included studies were conducted in Chinese populations, which presented a high risk of selection bias. Second, most of the trials included were of low quality with the information on allocation concealment, blinding, dropouts, and intention to treat missing, which might have concealed potential selection or detection bias. Besides that, differences in the quality of trials, intervention methods, different dosages of MTX and LEF, and treatment duration were responsible for the heterogeneity. Finally, there were only two RCTs that discussed the influence of TGP on lipid metabolism, making it hard to sum up the lipid-regulating benefit. Consequently, the conclusions of this study should be carefully interpreted. Treatment dose, treatment duration, and the difference in disease activity of RA might lead to differences in the treatment effect. These factors should be considered to resolve the issues in further experiments. Because of the low quality of the included studies, the overall effects still need further verification in more clinical studies with a larger sample and better methodological quality.

\section{Conclusion}

Our meta-analysis suggested that TGP combined with MTX and LEF might be more effective and safer than MTX and LEF treatment for the treatment of active RA. Besides its efficacy-enhancing and 


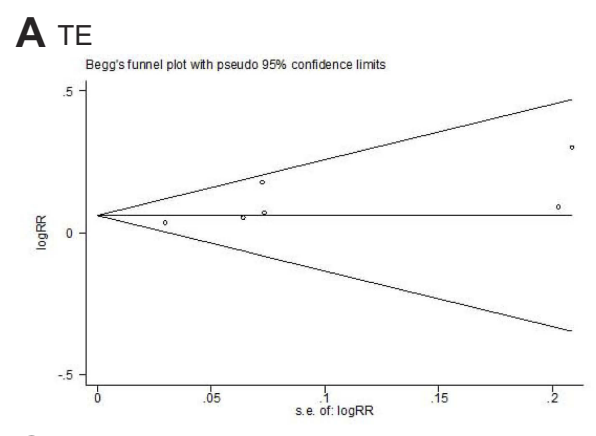

B ESR

C CRP
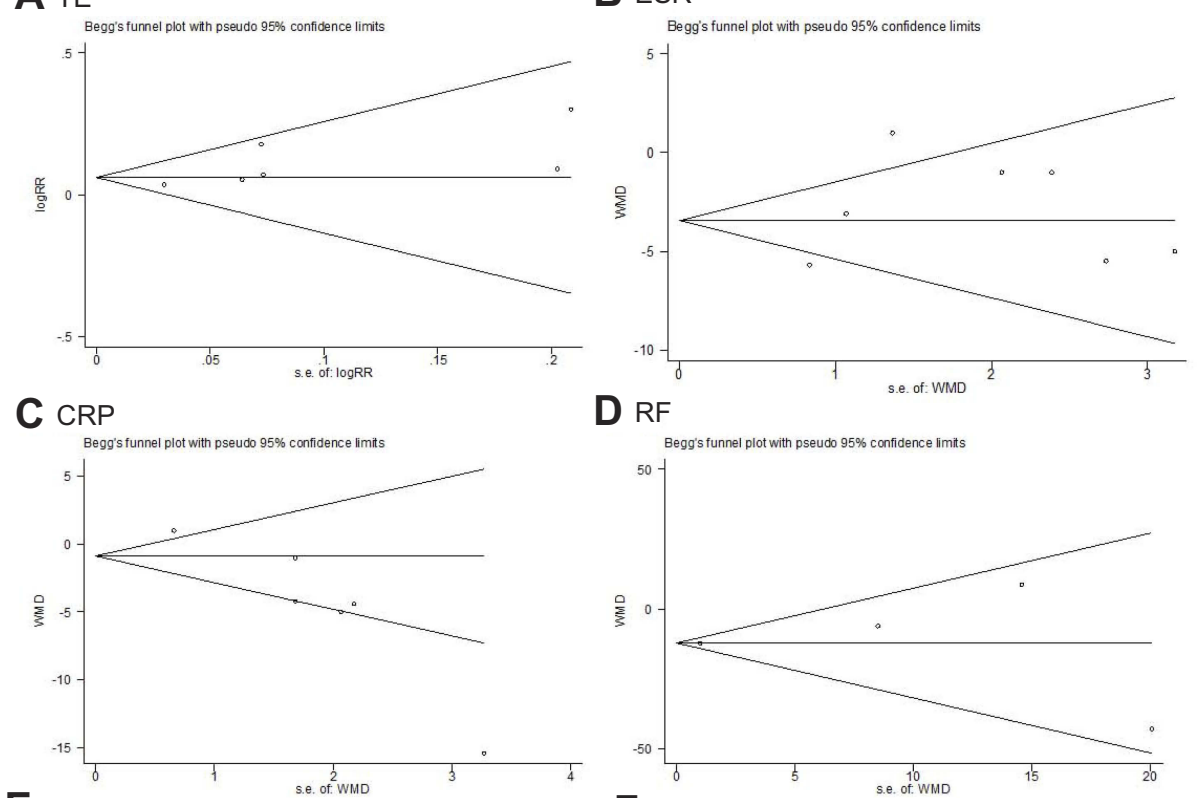

E DAS28

D RF
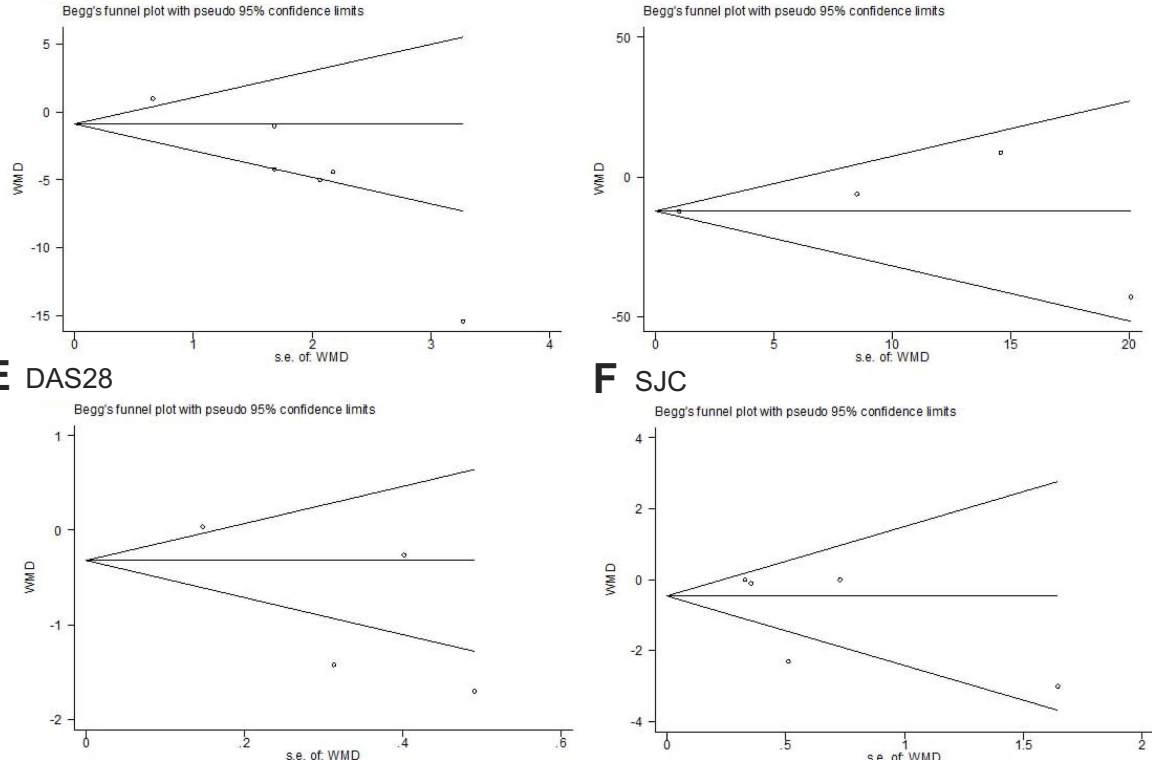

F SJC
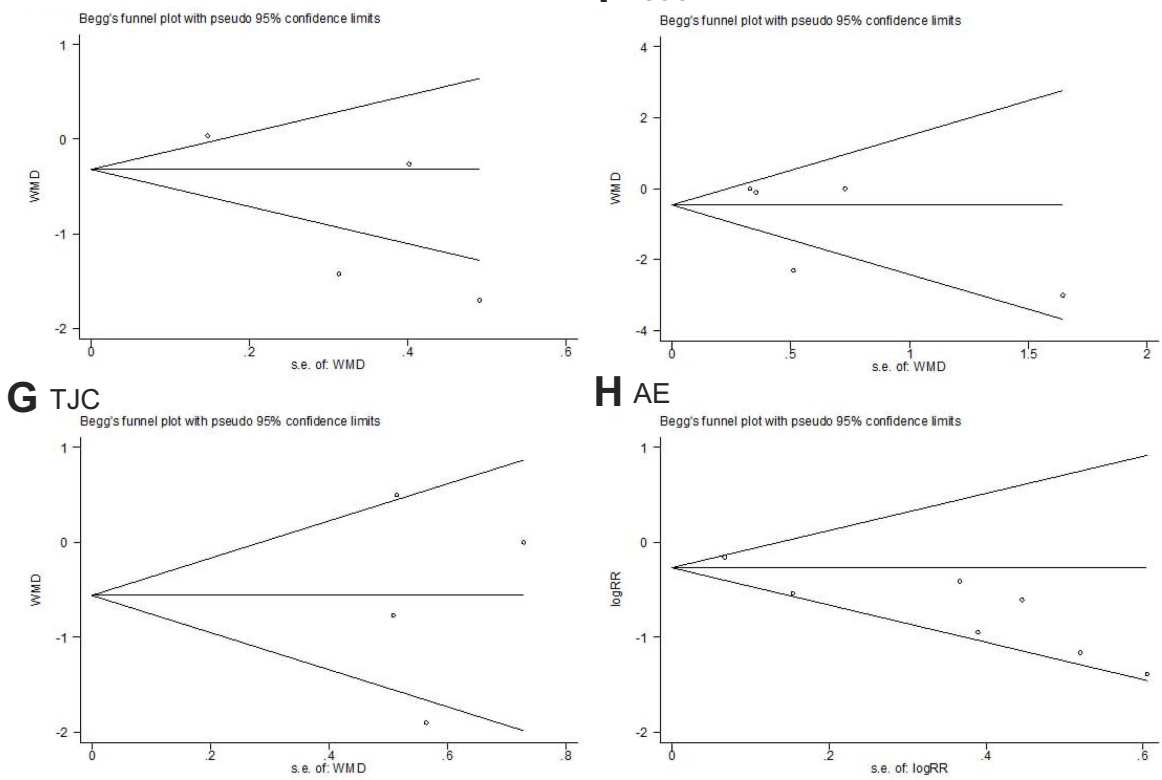

$\mathrm{H} A \mathrm{E}$

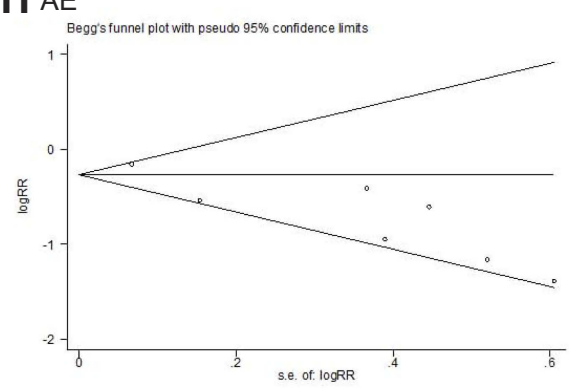

Figure 9 Begg's regression analyses for publication bias. (A) TE; (B) ESR; (C) CRP; (D) RF; (E) DAS28; (F) SJC; (G) TJC; (H) AE.

Abbreviations: ESR, erythrocyte sedimentation rate; CRP, C-reactive protein; RF, rheumatoid factor; DAS28, disease activity score in 28 joints; SJC, swollen joint count; TJC, tender joint count; $A E$, adverse event.

hepatoprotective effect for RA treatment, TGP may benefit the metabolic profile and lower CVD occurrences without causing major side effects. Thus, we suggest its application as an adjuvant combined with other csDMARDs such as MTX and LEF. Further clinical trials with a larger sample and better methodological quality are warranted to clarify the potential benefits of TGP for RA.

\section{Acknowledgments}

We acknowledge and thank Jing Gong and Fen Yuan for providing technical help. This article was supported by the National Natural Science Foundation of China (No. 81573802, 81503426, 81874383).

\section{Disclosure}

The authors report no conflicts of interest in this work. 


\section{References}

1. Cross M, Smith E, Hoy D, et al. The global burden of rheumatoid arthritis: estimates from the global burden of disease 2010 study. Ann Rheum Dis. 2014;73(7):1316-1322. doi:10.1136/annrheumdis-2013-204627

2. Li R, Sun J, Ren LM, et al. Epidemiology of eight common rheumatic diseases in China: a large-scale cross-sectional survey in Beijing. Rheumatology (Oxford). 2012;51(4):721-729. doi:10.1093/ rheumatology $/$ ker 370

3. Smolen JS, Landewe R, Bijlsma J, et al. EULAR recommendations for the management of rheumatoid arthritis with synthetic and biological disease-modifying antirheumatic drugs: 2016 update. Ann Rheum Dis. 2017;76(6):960-977. doi:10.1136/annrheumdis-2016-210715

4. Katchamart W, Trudeau J, Phumethum V, Bombardier C. Efficacy and toxicity of methotrexate (MTX) monotherapy versus MTX combination therapy with non-biological disease-modifying antirheumatic drugs in rheumatoid arthritis: a systematic review and meta-analysis. Ann Rheum Dis. 2009;68(7):1105-1112. doi:10.1136/ ard.2008.099861

5. Nam JL, Takase-Minegishi K, Ramiro S, et al. Efficacy of biological disease-modifying antirheumatic drugs: a systematic literature review informing the 2016 update of the EULAR recommendations for the management of rheumatoid arthritis. Ann Rheum Dis. 2017;76 (6):1113-1136. doi:10.1136/annrheumdis-2016-210713

6. Singh JA, Hossain A, Tanjong GE, Mudano AS, Tugwell P, Wells GA. Biologic or tofacitinib monotherapy for rheumatoid arthritis in people with traditional disease-modifying anti-rheumatic drug (DMARD) failure: a cochrane systematic review and network meta-analysis (NMA). Cochrane Database Syst Rev. 2016;11: D12437. doi:10.1002/14651858.CD011360.pub2

7. Zhang W, Dai SM. Mechanisms involved in the therapeutic effects of Paeonia lactiflora Pallas in rheumatoid arthritis. Int Immunopharmacol. 2012;14(1):27-31. doi:10.1016/j.intimp.2012.06.001

8. Parker S, May B, Zhang C, Zhang AL, Lu C, Xue CC. A pharmacological review of bioactive constituents of Paeonia lactiflora Pallas and Paeonia veitchii Lynch. Phytother Res. 2016;30 (9):1445-1473. doi:10.1002/ptr.5653

9. Jia XY, Chang Y, Sun XJ, et al. Total glucosides of paeony inhibit the proliferation of fibroblast-like synoviocytes through the regulation of $G$ proteins in rats with collagen-induced arthritis. Int Immunopharmacol. 2014;18(1):1-6. doi:10.1016/j. intimp.2013.09.007

10. Chen Z, Li X, Li Z, Xu L, Li X. Reduced hepatotoxicity by total glucosides of paeony in combination treatment with leflunomide and methotrexate for patients with active rheumatoid arthritis. Int Immunopharmacol. 2013;15(3):474-477. doi:10.1016/j. intimp.2013.01.021

11. Xiang N, Li X, Zhang M, et al. Total glucosides of paeony can reduce the hepatotoxicity caused by Methotrexate and Leflunomide combination treatment of active rheumatoid arthritis. Int Immunopharmacol. 2015;28(1):802-807. doi:10.1016/j.intimp.2015.08.008

12. Moher D, Shamseer L, Clarke M, et al. Preferred reporting items for systematic review and meta-analysis protocols (PRISMA-P) 2015 statement. Syst Rev. 2015;4:1. doi:10.1186/2046-4053-4-1

13. Shi LP, Zhu MH, He Y. Effect of total glucosides of paeony combined with leflunomide on IL-1 $\beta$, IL- 6 and TNF- $\alpha$ in rheumatoid arthritis. Chin J Pract Med. 2011;38(3):1-3.

14. Wang YP. Therapeutic effect and comparison of liver damage of two combined schemes on rheumatoid arthritis. Public Medical Forum Magazine. 2012;16(13):1644-1646.

15. Zheng HM, Jue HY, Yang YH. Effects of total glucosides of paeony on lipid profile in patients with rheumatoid arthritis. Chin J Basic Med Traditional Chin Med. 2014;20(06):832-834.
16. Wang Y. Effect of combination of total glucosides of paeony and immunosuppressive on transaminase in treatment of rheumatoid arthritis. J Clin Med Lit. 2015;2(11):2132.

17. Zhang H, Fan HT. Efficacy of total glucosides of paeony on blood lipid in patients with rheumatoid Arthritis. Chin J Clin Pharmacol. 2016;32(07):597-599.

18. Tan K, Xiang Y, Yuan L, Dai YF. Therapeutic effect of total glucosides of paeony, methotrexate and leflunomide in the treatment of severe active rheumatoid arthritis. World Latest Med Inf. 2018;18 (06):159-160.

19. Higgins JPT, Green S, eds. Cochrane Handbook for Systematic Reviews of Interventions. Version 5.1.0 [updated March 2011]. London: The Cochrane Collaboration; 2011.

20. Billix M. Effects of total glucoseides of paeony in combination treatment with methotrexate and leflunomide on liver function for rheumatoid arthritis. China Health Care \& Nutrition. 2017;09 (02):262-263.

21. Yu WJ, Xu J, Liang Y, Li M, Sha H. Clinical observation of total paeony glycoside capsule combined with methotrexate and leflunomide in the treatment of rheumatoid arthritis. Sichuan Med J. 2018;39 (01):83-85.

22. Wang Y, Li JX, Li XF. Comparison of efficacy and safety of total glucosides of paeony combined with methotrexate and leflunomind in the treatment of rheumatoid arthritis. National Medical Frontiers of China. 2011;6(19):16-17.

23. Li ZJ, Xu L, Li XP, et al. Total glucosides of paeony can affect hepatic dysfunction of patients with moderate or severe liver damage caused by methotrexate and leflunomide in rheumatoid arthritis patients. Chinese Journal of Rheumatology. 2013;17(3):169-172.

24. Xu HM, Wei W, Jia XY, Chang Y, Zhang L. Effects and mechanisms of total glucosides of paeony on adjuvant arthritis in rats. J Ethnopharmacol. 2007;109(3):442-448. doi:10.1016/j.jep.2006.08.019

25. Zhou Z, Lin J, Huo R, et al. Total glucosides of paeony attenuated functional maturation of dendritic cells via blocking TLR4/5 signaling in vivo. Int Immunopharmacol. 2012;14(3):275-282. doi:10.1016/j.intimp.2012.07.012

26. Xu XX, Qi XM, Zhang W, et al. Effects of total glucosides of paeony on immune regulatory toll-like receptors TLR2 and 4 in the kidney from diabetic rats. Phytomedicine. 2014;21(6):815-823. doi:10.1016/ j.phymed.2013.12.003

27. Zhang XJ, Li Z, Leung WM, Liu L, Xu HX, Bian ZX. The analgesic effect of paeoniflorin on neonatal maternal separation-induced visceral hyperalgesia in rats. J Pain. 2008;9(6):497-505. doi:10.1016/j. jpain.2007.12.009

28. Yang DQ, You LP, Song PH, Zhang LX, Bai YP. A randomized controlled trial comparing total glucosides of paeony capsule and compound glycyrrhizin tablet for alopecia areata. Chin J Integr Med. 2012;18(8):621-625. doi:10.1007/s11655-012-1173-0

29. Taurog JD, Chhabra A, Colbert RA. Ankylosing Spondylitis and axial Spondyloarthritis. $N$ Engl J Med. 2016;375(13):1303.

30. Zhou L, Cao T, Wang Y, et al. Clinical observation on the treatment of oral lichen planus with total glucosides of paeony capsule combined with corticosteroids. Int Immunopharmacol. 2016;36:106-110. doi:10.1016/j.intimp.2016.03.035

31. Luo J, Jin DE, Yang GY, et al. Total glucosides of paeony for rheumatoid arthritis: a systematic review of randomized controlled trials. Complement Ther Med. 2017;34:46-56. doi:10.1016/j.ctim.2017.07.010

32. Jin L, Li C, Li Y, Wu B. Clinical efficacy and safety of total glucosides of paeony for primary Sjogren's syndrome: a systematic review. Evid Based Complement Alternat Med. 2017;2017:3242301. doi:10.1155/2017/3242301

33. De Vera MA, Choi H, Abrahamowicz M, Kopec J, Lacaille D. Impact of statin discontinuation on mortality in patients with rheumatoid arthritis: a population-based study. Arthritis Care Res (Hoboken). 2012;64(6):809-816. doi:10.1002/acr.21643 
34. Primdahl J, Clausen J, Horslev-Petersen K. Results from systematic screening for cardiovascular risk in outpatients with rheumatoid arthritis in accordance with the EULAR recommendations. Ann Rheum Dis. 2013;72(11):1771-1776. doi:10.1136/annrheumdis-2013-203682

35. Li J, Chen CX, Shen YH. Effects of total glucosides from paeony (Paeonia lactiflora Pall) roots on experimental atherosclerosis in rats. J Ethnopharmacol. 2011;135(2):469-475. doi:10.1016/j.jep.2011.03.045
36. Zhang L, Yang B, Yu B. Paeoniflorin protects against nonalcoholic fatty liver disease induced by a high-fat diet in mice. Biol Pharm Bull. 2015;38(7):1005-1011. doi:10.1248/bpb.b14-00892

37. Li X, Shen J, Zhong Z, et al. Paeoniflorin ameliorates schistosomiasis liver fibrosis through regulating IL-13 and its signalling molecules in mice. Parasitology. 2010;137(8):1213-1225. doi:10.1017/S0031 18201000003X

\section{Publish your work in this journal}

Drug Design, Development and Therapy is an international, peerreviewed open-access journal that spans the spectrum of drug design and development through to clinical applications. Clinical outcomes, patient safety, and programs for the development and effective, safe, and sustained use of medicines are a feature of the journal, which has also been accepted for indexing on PubMed Central. The manuscript management system is completely online and includes a very quick and fair peer-review system, which is all easy to use. Visit http://www. dovepress.com/testimonials.php to read real quotes from published authors. 